\title{
Quality of muffins enriched with upcycled defatted sunflower seed flour
}

Article

Accepted Version

Grasso, S., Liu, S. and Methven, L. (2020) Quality of muffins enriched with upcycled defatted sunflower seed flour. LWT Food Science and Technology, 119. 108893. ISSN 0023-6438 doi: https://doi.org/10.1016/j.Iwt.2019.108893 Available at https://centaur.reading.ac.uk/87557/

It is advisable to refer to the publisher's version if you intend to cite from the work. See Guidance on citing.

To link to this article DOI: http://dx.doi.org/10.1016/j.Iwt.2019.108893

Publisher: Elsevier

All outputs in CentAUR are protected by Intellectual Property Rights law, including copyright law. Copyright and IPR is retained by the creators or other copyright holders. Terms and conditions for use of this material are defined in the End User Agreement.

\section{www.reading.ac.uk/centaur}

\section{CentAUR}

Central Archive at the University of Reading

Reading's research outputs online 


\title{
Quality of muffins enriched with upcycled defatted sunflower seed flour
}

(i) The corrections made in this section will be reviewed and approved by journal production editor.

Simona Grasso* simona.grasso@ucdconnect.ie, Shuyi Liu, Lisa Methven

School of Agriculture, Policy and Development, University of Reading, PO Box 237, Earley Gate, Reading, RG6 6AR, UK

${ }^{*}$ Corresponding author.

\begin{abstract}
There is an increased interest and need to valorise food industry by-products by reincorporating them into the food chain. Defatted sunflower seed flour (DSSF), obtained from a by-product of the sunflower industry, has an attractive nutritional profile. The aim of this study was to evaluate the effects of incorporating DSSF at $15 \%$ and $30 \%$ in muffins as replacement for wheat flour. Proximate composition, physical analyses and sensory quality through Quantitative Descriptive Analysis (QDA) were explored and compared to a control DSSF-free recipe. DSSF in muffins led to increased protein and ash content and decreased carbohydrate content. DSSF did not affect bake loss, it increased muffins' height and pore density, and decreased their springiness. DSSF had an effect on colour, making muffins darker and less yellow than control. QDA results showed that muffins containing $15 \%$ DSSF had a profile closer to control than those containing $30 \%$ DSSF could be potentially exploited as an ingredient in cakes and muffins since its addition mainly led to neutral or positive physico-chemical changes. Future reformulation work could focus on optimising the sensory quality of DSSF fortified muffins with inclusion up to $15 \%$, masking some of the atypical colours, aromas and flavours, and evaluating consumer acceptance.
\end{abstract}

Keywords: Defatted sunflower seed flour; Image analysis; Sensory analysis; Muffins; By-product valorisation

\section{Introduction}


Sunflower is the fourth crop in the world for oil production after palm, soybean and rapeseed oil, with 15.8 million tonnes produced in 2014 (FAO, 2018). The production of sunflower oil results in a by-product called sunflower meal or cake, which can represent up to $36 \%$ of the mass of the processed seeds (Yegorov, Turpurova, Sharabaeva, \& Bondar, 2019). This by-product contains protein 40-50 g/100 g (González-Pérez et al., 2002), essential amino acids (such as lysine, methionine, cysteine and tryptophan), fibre, minerals and B group vitamins (Yegorov et al., 2019). Currently this by-product is used in the livestock feed industry (Anal, 2017), as plant fertilizer or soil compost (Teh \& Bekhit, 2015). Considered an alternative and economic source of proteins with good nutritional quality (Salgado, Molina Ortiz, Petruccelli, \& Mauri, 2012), sunflower cake is interesting to use as human food and some companies have already started to commercialise defatted sunflower seed flour (DSSF) with small particle size (US mesh 100) for food applications (Planetarians, 2018).

A potential application for DSSF could be in baked goods such as muffins, cakes or biscuits, which are versatile and popular foods due to their taste. Products such as muffins are usually high in sugar and fat but low in fibre, antioxidants and minerals (Heo, Kim, Lee, \& Moon, 2019). Food industry by-products such as DSSF could represent an opportunity to manufacture healthier baked goods while lowering the environmental impact associated to the by-product disposal. Several studies have incorporated fruit and vegetable by-products in muffins and investigated the quality of the resulting products. Some recent examples include by-products from pecan nut, kimchi, coffee silverskin, goji berry, sour cherry, strawberry, raspberry and black currant; mainly used for their fibre, fat and/or antioxidant contents (Ateş \& Elmac1, 2019; Bajerska, MildnerSzkudlarz, Górnaś, \& Seglina, 2016; Bora, Ragaee, \& Abdel-Aal, 2019; Górnaś et al., 2016; Heo et al., 2019; Marchetti, Califano, \& Andrés, 2018; Mildner-Szkudlarz et al., 2016). Exhaustive reviews on this topic are also available (Gómez \& Martinez, 2018; Martins, Pinho, \& Ferreira, 2017). The high protein content and small particle size of DSSF, make it different from other fruit and vegetable by-products and for these reasons the use of DSSF in baked goods is particularly interesting. A previous study utilising sunflower meal protein isolate to replace wheat flour in bread (Mohammed et al., 2018) found that only 1\% inclusion was acceptable whereas higher levels led to reduced bread volume and increased hardness. However, bread requires a high level of "strong" wheat flour (higher in wheat gluten proteins) in order to form an elastic structure that can lead to control gas release and high loaf volume. As muffin doughs require less elasticity, have a lower flour content and higher amounts of other masking ingredients, such as fats and sugars (Gómez \& Martinez, 2018), it is likely that the inclusion of DSSF in muffins could reach higher rates than bread. In bread, it has been reported that wheat flour replacement by fruit and vegetable by-products does not usually exceed 10\% (Gómez \& Martinez, 2018; Martins et al., 2017).

No studies are currently available on the incorporation of DSSF in cakes or muffins, therefore the aim of this study was to evaluate the effect of incorporating DSSF at $15 \%$ and $30 \%$ on the chemical, physical and sensory quality of muffins.

\section{Materials and methods}

\subsection{Ingredients}


All recipes were made with the same common ingredients purchased from a local retailer (Sainsbury's, Reading, UK). The ingredients were plain flour (composition from manufacturer: fat $1 \mathrm{~g} / 100 \mathrm{~g}$, carbohydrate $71.7 \mathrm{~g} / 100 \mathrm{~g}$, fibre $3.5 \mathrm{~g} / 100 \mathrm{~g}$, protein $9.7 \mathrm{~g} / 100 \mathrm{~g}$ ), caster sugar, whole free range medium eggs, dried skimmed milk powder, sunflower oil, salt and baking powder. DSSF (composition from manufacturer: fat $1 \mathrm{~g} / 100 \mathrm{~g}$, carbohydrate $48 \mathrm{~g} / 100 \mathrm{~g}$, fibre $18 \mathrm{~g} / 100 \mathrm{~g}$, protein $35 \mathrm{~g} / 100 \mathrm{~g}$ ), US mesh 100, was donated by the company Planetarians (Palo Alto, CA, USA).

\subsection{Muffin manufacture}

A reference muffin recipe from Ateş and Elmacı (2019) was employed as control. The following ingredients made up $100 \mathrm{~g}$ of control dough: $28.2 \mathrm{~g}$ sugar, $24.4 \mathrm{~g}$ wheat flour, $20.7 \mathrm{~g}$ whole egg, $15.8 \mathrm{~g}$ sunflower oil, $8.6 \mathrm{~g}$ water, $1.2 \mathrm{~g}$ skimmed milk powder, $0.9 \mathrm{~g}$ baking powder and $0.2 \mathrm{~g}$ salt. Muffins containing DSSF were prepared by replacing wheat flour with DSSF at 15\% (3.7 g/100 g) and 30\% (7.3 g/100 g) respectively. Samples were coded as control (recipe without DSSF), DSSF 15 and DSSF30 for recipes where $15 \%$ or $30 \%$ of wheat flour was replaced with DSSF.

For the muffin manufacture, the same procedure from Ateş and Elmac1 (2019) was followed: whole egg and sugar were mixed for 1 min with a hand-held mixer (Kenwood Hand Mixer HM520, Reading, UK) at speed one. Then all the other ingredients were added: sunflower oil, milk powder dissolved in water, flour (for control muffins) or flour and DSSF (for DSSF15 and DSSF30 muffins), baking powder, salt. The ingredients were mixed for 3 minthree minutes at speed four. Portions of $40 \mathrm{~g} \pm 0.5 \mathrm{~g}$ of batter were added to paper muffin cases and then placed onto metallic muffin trays. Muffins were baked in groups of twelve units in a pre-heated oven ventilated oven (Kwick_Co, Salva, Gipuzkoa, Spain) for $20 \mathrm{~min}$ at $190^{\circ} \mathrm{C}$. After $1 \mathrm{~h}$ of cooling time, the muffins were kept in sealed plastic bags to prevent moisture loss.

\subsection{Proximate composition and water activity (Aw)}

The moisture, protein, fat and ash content of control and DSSF fortified muffins were determined using methods from the Association of Official Analytical Chemists (AOAC, 2000). The total content of carbohydrates was calculated by difference: 100 - (moisture + ash + protein + fat). Water activity was measured using a water activity meter (AW-DIO, Rotronic, Crawley, UK). Compositional analyses and Aw were determined in triplicate for each recipe (3) and for each batch (2).

\subsection{Physical characteristics}

\subsubsection{Bake loss and height}

Batter weights and muffin weights were recorded for each muffin. Muffin heights were recorded using a digital caliper. Weights and heights were taken on twelve muffins for each recipe (3) and each batch (2). The bake loss was calculated using the below formula from Heo et al. (2019):

Bake loss $(\mathrm{g} / 100 \mathrm{~g})=\frac{(\text { Batter weight }- \text { Muffin weight }) g}{\text { Batter weight }(g)} \times 100$ 


\subsubsection{Crumb texture}

Texture Profile Analysis was performed on muffin cubes cut from the centre $(2.5 \mathrm{~cm} \times 2.5 \mathrm{~cm})$. The samples were compressed using a TA-XT2i Texture Analyser (Stable Micro Systems, London, UK) using a probe with $75 \mathrm{~mm}$ diameter (SMS P/75) and a test speed of $1 \mathrm{~mm} / \mathrm{s}$. The probe compressed the sample to $25 \%$ of the product's height. It held this distance for $30 \mathrm{~s}$ and then it returned to the starting position. Two variables were measured, firmness (defined as the force in $g$ required to compress the muffin to a pre-set distance, in this case $25 \%$ ) and springiness (in \%, the force after $30 \mathrm{~s}$ divided by the maximum force; result multiplied by 100). The closer the resulting value is to $100 \%$, the higher springiness the product has. Measurements were carried out on twelve muffins for each recipe (3) and each batch (2).

\subsubsection{Crumb structure}

Digital image analysis was used to characterise the crumb structure similarly to Marchetti et al. (2018). The images of muffin halves were captured using a flat-bed scanner (HP 4500, Palo Alto, USA). Obtained images were analysed using the software Image $J$ (National Institutes of Health, New York, USA, http://rsb.info.nih.go v/ij) that uses the contrast between the pores and the solid parts of the image. Scanned colour images were first converted to gray scale and binarised to obtain the pore area fraction (total pore area in $\mathrm{cm}^{2} /$ total area of the muffin in $\mathrm{cm}^{2}$ ), the pore density (number of pores $/ \mathrm{cm}^{2}$ ) and the pore specific perimeter (the sum of all pore perimeters/total area of the muffin in $\left.\mathrm{cm}^{2}\right)$. The pore size distribution ( $\left.\% \mathrm{v} / \mathrm{v}\right)$ was analysed as histograms showing pore sizes divided in twelve diameter ranges. Measurements were carried out on twelve muffin halves for each recipe (3) and each batch (2).

\subsubsection{Crust and crumb colour}

Colour determinations were performed using a colorimeter (CR-400, Konica, Minolta, Japan), calibrated using a white standard plate. The values measured were $L^{*}$ (white 100/black 0), a* values (red positive/green negative) and $b^{*}$ values (yellow positive/blue negative). Colour readings were taken on twelve muffins for each recipe (3) and each batch (2), on three points of each muffin's external crust surface and on three points on each muffin's internal crumb surface.

\subsection{Sensory evaluation}

Sensory profiling of muffins was conducted by a panel of eight highly trained panelists using Quantitative Descriptive Analysis (QDA). Panelists were selected and trained in accordance with ISO standards for sensory analysis (ISO 8586:2012) and are subject to performance monitoring (ISO 11132:2012). A consensus vocabulary of thirty-one descriptors was developed to characterise the samples; under the modalities appearance (6), aroma (6), taste and flavour (10), mouthfeel (4) and after-effects (5), using reference standards where required. The purpose of the sensory profiling was to provide a measure for changes in muffin descriptors occurring with change in formulation. Descriptor scoring was done using unstructured line-scales (scale 0-100) using the Compusense ${ }^{\circledR}$ software (Compusense, Ontario, Canada). Panellists were seated in individual testing booths under artificial daylight. Samples (half muffin per person per sample) were presented 
in a balanced order, randomly allocated and single-blinded using three-digit number codes. Warm filtered water was used as a palate cleanser and the time delay between samples (post after-effects scoring) was $30 \mathrm{~s}$. Muffin scoring was carried out in duplicates on two consecutive days. Muffins were manufactured the day before each scoring and stored in sealed plastic bags until they were tested.

\subsection{Statistical analysis}

The baking experiment was repeated twice on two different days. Statistical analyses were carried out using analysis of variance (ANOVA). Multiple pairwise comparisons were performed using Tukey's HSD at a significance level of $\mathrm{P}<0.05$. For analytical data SPPS software was used (V24, SPSS Inc., Chicago, IL, USA). For sensory data, a two-way ANOVA was carried out using SenPAQ software (Qi Statistics Ltd., Reading, UK). The panellists were fitted as random effects and the samples were fixed effects. The treatment effects (samples and assessors) were tested against the sample by assessor interaction.

\section{Results and discussion}

\subsection{Proximate composition and Aw}

The proximate composition and Aw of control and DSSF fortified muffins are shown in Table 1. Protein and ash contents were significantly higher in DSSF fortified muffins compared to control $(+19 \%$ in DSSF10 and $+37 \%$ in DSSF30 for protein content, $+24 \%$ in DSSF 15 and $+47 \%$ in DSSF30 for ash content). The carbohydrate content was significantly lower in DSSF fortified muffins, although to a smaller extent than ash and protein (compared to control $-1.7 \%$ in DSSF15 and $-4.6 \%$ in DSSF30). In DSSF fortified muffins, the protein and ash contents increased when DSSF inclusion increased from $15 \%$ to $30 \%$. The protein increase is due to the high protein content of DSSF $(35 \mathrm{~g} / 100 \mathrm{~g}$ ), while the increase in ash content is related to the mineral content of DSSF. According to the literature (Ratcliff, 1977), sunflower oil cake on a dry basis contains $0.48 \mathrm{~g} / 100 \mathrm{~g}$ calcium, $0.84 \mathrm{~g} / 100 \mathrm{~g}$ phosphorus, $0.44 \mathrm{~g} / 100 \mathrm{~g}$ magnesium and $3.49 \mathrm{~g} / 100 \mathrm{~g}$ potassium. In terms of fat and moisture content, control and DSSF15 muffins were similar, while DSSF30 had higher fat and lower moisture content than control and DSSF15 due to the higher DSSF inclusion level. The Aw was similar in DSSF fortified muffins and significantly higher in control muffins, indicating that DSSF inclusion lowered the amount or free/unbound or available water in the muffins.

alt-text: Table 1

Table 1

The presentation of Tables and the formatting of text in the online proof do not match the final output, though the data is the same. To preview the actual presentation, view the Proof.

Proximate composition and Aw of control and defatted sunflower seed flour fortified muffins.

\begin{tabular}{|c|c|c|c|}
\hline Parameters & Control & DSSF15 & DSSF30 \\
\hline Carbohydrate (g/100 g) & $65.60 \pm 0.51^{\mathrm{a}}$ & $64.50 \pm 0.14^{b}$ & $62.58 \pm 0.90^{c}$ \\
\hline
\end{tabular}




\begin{tabular}{|l|l|l|l|}
\hline Fat $(g / 100 \mathrm{~g})$ & $7.29 \pm 0.68^{\mathrm{b}}$ & $7.55 \pm 0.32^{\mathrm{b}}$ & $9.13 \pm 0.83^{\mathrm{a}}$ \\
\hline Protein $(\mathrm{g} / 100 \mathrm{~g})$ & $5.97 \pm 0.08^{\mathrm{c}}$ & $7.13 \pm 0.07^{\mathrm{b}}$ & $8.20 \pm 0.07^{\mathrm{a}}$ \\
\hline Ash $(\mathrm{g} / 100 \mathrm{~g})$ & $1.17 \pm 0.02^{\mathrm{c}}$ & $1.45 \pm 0.01^{\mathrm{b}}$ & $1.72 \pm 0.02^{\mathrm{a}}$ \\
\hline Moisture $(\mathrm{g} / 100 \mathrm{~g})$ & $19.97 \pm 0.46^{\mathrm{a}}$ & $19.38 \pm 0.45^{\mathrm{a}}$ & $18.38 \pm 0.42^{\mathrm{b}}$ \\
\hline Aw & $0.758 \pm 0.007^{\mathrm{a}}$ & $0.746 \pm 0.004^{\mathrm{b}}$ & $0.742 \pm 0.008^{\mathrm{b}}$ \\
\hline
\end{tabular}

Data are expressed as means $\pm \mathrm{SD}(\mathrm{n}=6)$. Values with the same letter in the same row are not significantly different at $\mathrm{P}<0.05$

\subsection{Physical characteristics}

Bake loss (Table 2) was not significantly different across the three recipes, although the bake loss was slightly higher in both DSSF fortified muffins. As explained by Marchetti et al. (2018), this parameter is of industrial interest, because the lower the bake loss, the higher the yield and therefore the product weight. Weight loss is the result of the release of water from the product during baking, which is related to the water holding capacity of the ingredients. DSSF recently was found to have a threefold higher water holding capacity than wheat flour, $2.21 \mathrm{~g}$ water $/ \mathrm{g}$ dry weight for DSSF versus $0.69 \mathrm{~g}$ water/g dry weight for wheat flour (Grasso, Omoarukhe, Wen, Papoutsis, \& Methven, 2019). Although the amount of water added to all recipes was the same $(8.6 \mathrm{~g} / 100 \mathrm{~g})$, wheat flour and DSSF contain different amounts of moisture. The wheat flour in this study contained around 14\% moisture, while it has been reported that DSSF has around 6\% moisture (Grasso et al., 2019). The lower moisture content of DSSF flour could explain why, although the water binding capacity of the defatted sunflower seed flour is significantly higher than wheat flour, DSSF fortified muffins did not show a lower bake loss compared to control.

alt-text: Table 2

Table 2

i The presentation of Tables and the formatting of text in the online proof do not match the final output, though the data is the same. To preview the actual presentation, view the Proof.

Physical characteristics of control and defatted sunflower seed flour fortified muffins.

\begin{tabular}{|c|c|c|c|}
\hline Parameters & Control & DSSF15 & DSSF30 \\
\hline Bake loss (g/100 g) & $10.99 \pm 0.50^{\mathrm{a}}$ & $11.22 \pm 0.57^{\mathrm{a}}$ & $11.26 \pm 0.43^{\mathrm{a}}$ \\
\hline Height (cm) & $3.81 \pm 0.20^{b}$ & $4.13 \pm 0.13^{\mathrm{a}}$ & $4.12 \pm 0.13^{\mathrm{a}}$ \\
\hline Firmness (g) & $180.20 \pm 32.25^{b}$ & $160.61 \pm 30.99^{b}$ & $201.21 \pm 29.26^{\mathrm{a}}$ \\
\hline Springiness $(\%)$ & $56.03 \pm 0.44^{\mathrm{a}}$ & $55.47 \pm 0.37^{b}$ & $53.39 \pm 0.38^{\mathrm{c}}$ \\
\hline Pore density (pores/cm²) & $1.85 \pm 0.81^{\mathrm{c}}$ & $4.53 \pm 2.87^{\mathrm{b}}$ & $7.02 \pm 2.44^{\mathrm{a}}$ \\
\hline Pore specific perimeter $\left(\mathrm{mm} / \mathrm{cm}^{2}\right)$ & $7.17 \pm 3.95^{\mathrm{c}}$ & $15.75 \pm 9.81^{b}$ & $25.40 \pm 8.77^{\mathrm{a}}$ \\
\hline
\end{tabular}


According to a recent review (Gómez \& Martinez, 2018), the incorporation of fruit and vegetable by-products is usually associated with decreased muffin or cake volume and height, however in the current study both DSSF fortified muffins had significantly higher height than control (Table 2). The authors of the review explain that the decrease in height is linked to the particle size. They claim that the typical particle size of wheat flour is $\leq 200 \mu \mathrm{m}$ (usually $\sim 100 \mu \mathrm{m}$ ), while fruit and vegetable by-products have larger particle size, usually smaller than $1 \mathrm{~mm}$ and ranging 400-600 $\mu \mathrm{m}$. Larger particles result in increased emulsion air bubbles, which leads to reduced emulsion stability and consequent loss of volume. The favourable height results of the present study might be partly explained by particle size, as DSSF has particle size of $149 \mu \mathrm{m}$ (US mesh 100), which is smaller than the average values reported by the literature for fruit and vegetable by-products. A second reason why the product's height increased compared to control muffins, might be related to the high protein content of DSSF. Other authors have reported heights higher than control muffins when incorporating protein sources such as egg white protein (Matos, Sanz, \& Rosell, 2014) and isolates from kidney bean, pea and amaranth (Shevkani \& Singh, 2014) in muffins. The added protein might have enhanced the viscoelasticity of the batter, which retained more of the air incorporated during mixing or more of the $\mathrm{CO}_{2}$ produced from the baking powder. Previous findings by Shchekoldina and Aider (2014) on bread dough showed that sunflower meal protein isolates had a strengthening effect on wheat gluten due to protein-protein electrostatic interaction between the wheat and sunflower protein components.

In terms of firmness, control and DSSF15 muffins were similar, while DSSF30 muffins were significantly firmer than the other two formulations (Table 2). Other authors have reported variable effects on muffin's hardness when adding proteins (Matos et al., 2014; Shevkani \& Singh, 2014). The higher fibre content in DSSF30 fortified muffins might have contributed to the increase in firmness. Harder texture when adding several fibre-rich fruit and vegetable by-products to sweet bakery products has been reported in recent reviews (Gómez \& Martinez, 2018; Martins et al., 2017). Springiness results showed that control muffins had the highest values, while both DSSF fortified muffins were significantly less springy than control. The higher the DSSF content, the lower the springiness. Springiness is associated with fresh, aerated and elastic texture, with high springiness values reflecting better quality muffins (Sanz, Salvador, Baixauli, \& Fiszman, 2009; Shevkani, Kaur, Kumar, \& Singh, 2015). These results are in contrast with those by Shevkani and Singh (2014) and Matos et al. (2014) who reported that springiness increased as protein inclusion rose in muffins. The lower springiness of DSSF fortified muffins could be explained with the pore density results from image analysis (Table 2).

An image of the internal and external appearance of the muffins is shown in Fig. 1. Image analysis results showed that control muffins had the lowest pore density, while both DSSF fortified muffins had significantly higher pore densities than control. The pore density increased with increasing DSSF content and the same was true for the pore specific perimeter. Pore area fraction was highest in DSSF30 muffins, but statistically similar in control and DSSF15 muffins, although numerically the pore area fraction of DSSF15 was double that of control. The higher the area fraction, the more sponge-like the crumb is (Marchetti et al., 2018). From the pore 
size distribution graphs in Fig. 2, it seems that the presence of DSSF affected the pore distribution, leading to an increase in pores with diameter $0.21-0.5 \mathrm{~mm}$. The increased variation in pore size has been associated with irregular cake crumbs (Pateras, Rosenthal, Howells, \& Marshall, 1990). These results on image analysis might help to explain the springiness decrease observed. With DSSF inclusion the number and area of pores increased dramatically, which resulted in the samples being less able to recover after deformation and therefore spring back less than control due to their extreme airiness.

alt-text: Fig. 1

\section{Fig. 1}

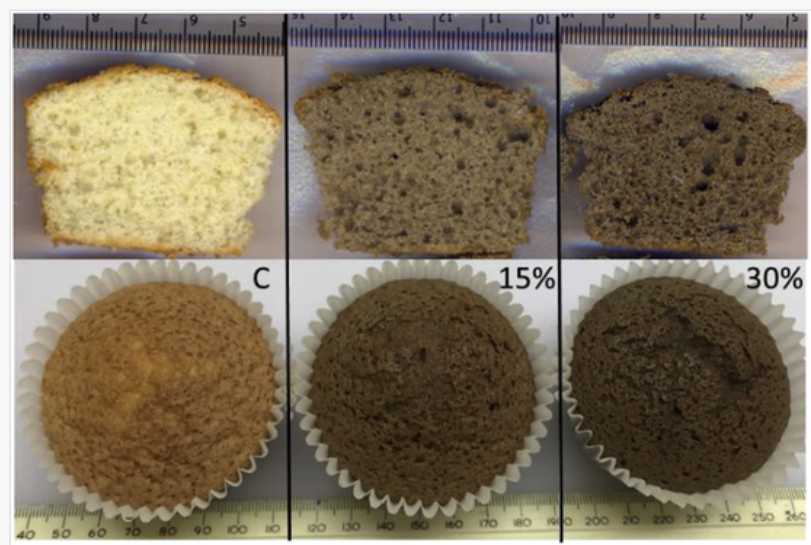

Internal and external appearance of control and defatted sunflower seed flour fortified muffins.

alt-text: Fig. 2

Fig. 2 

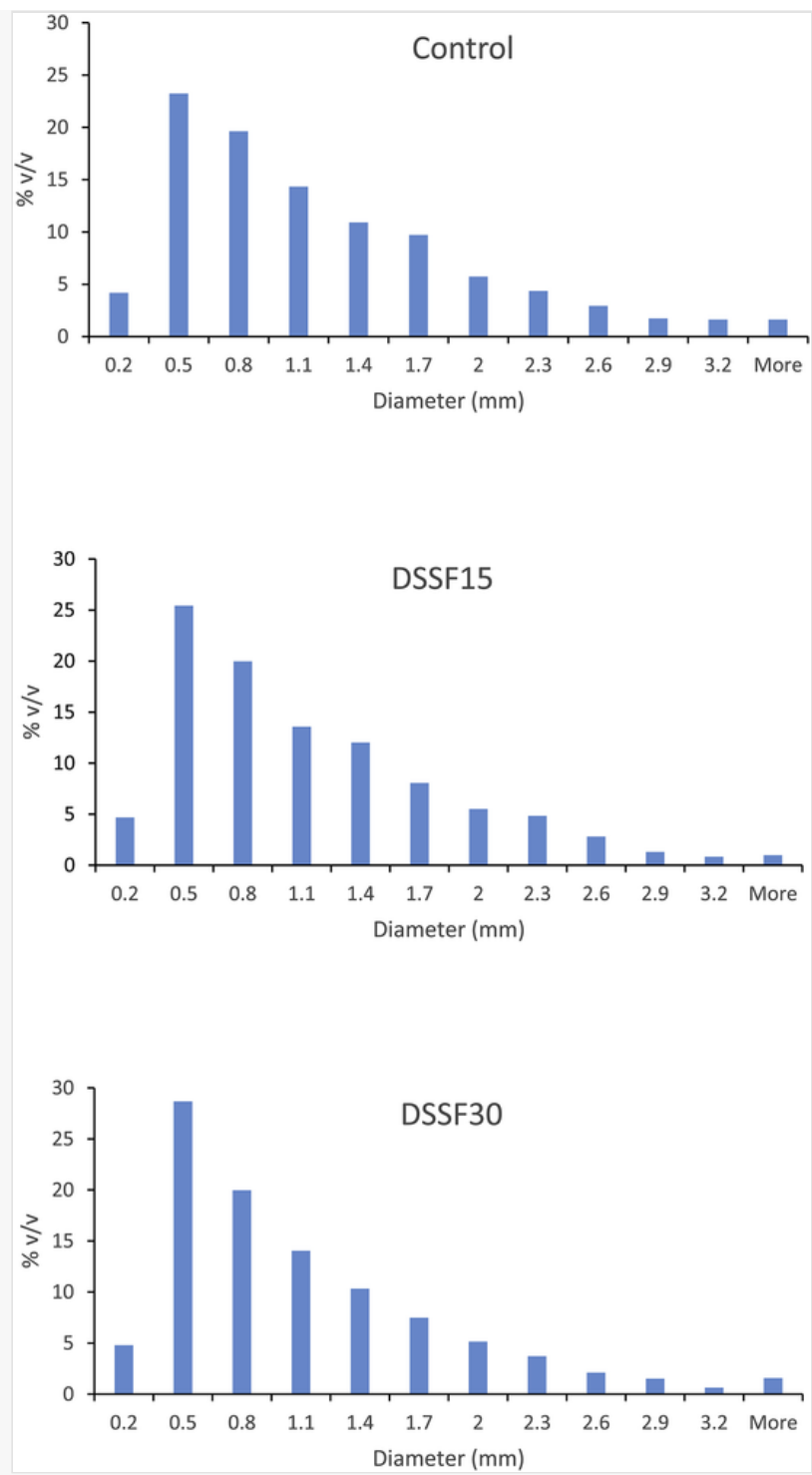

Pore size distribution of control and defatted sunflower seed flour fortified muffins.

Colour measurement results are shown in Table 3 and an image showing the internal and external appearance of the muffins is shown in Fig. 1. All crust colour parameters were highest in control muffins and decreased with increasing DSSF content. This indicates that DSSF fortified muffin crusts were darker, less red and less yellow than control. As for the crumb colour, this strongly depends on the raw components, since the core crumb temperature reached is not high enough to result in Maillard or caramelisation reactions as significant as those on the crust (Gómez \& Martinez, 2018; Marchetti et al., 2018). The crumb of DSSF fortified muffins was also darker and less yellow than control, but the colour differences were greater in the crumb than the crust due to more intense Maillard reaction. These results are easily understood considering the colour of $\operatorname{DSSF}\left(\mathrm{L}^{*} 62.99 \pm 0.12, \mathrm{a}^{*}=1.47 \pm 0.02, \mathrm{~b}^{*}=14.38 \pm 0.07\right)$ and wheat flour $\left(\mathrm{L}^{*}=93.93 \pm 0.36\right.$ $\left.\mathrm{a}^{*}=-0.79 \pm 0.06, \mathrm{~b}^{*}=11.45 \pm 0.15\right)$ and they are in accordance with those by Grasso et al. (2019), where DSSF was used in biscuits at $18 \%$ and $36 \%$. In general, colour changes are common when by-products are added to baked goods (Gómez \& Martinez, 2018), however through reformulation colour masking ingredients such as cocoa powder or whole wheat flour could potentially be used in muffins or cakes. 
alt-text: Table 3

Table 3

(i) The presentation of Tables and the formatting of text in the online proof do not match the final output, though the data is the same. To preview the actual presentation, view the Proof.

Colour properties of control and defatted sunflower seed flour fortified muffins.

\begin{tabular}{|c|c|c|c|c|}
\hline \multicolumn{2}{|l|}{ Parameters } & Control & DSSF15 & DSSF30 \\
\hline \multirow{3}{*}{ Crust } & $\mathrm{L}^{*}$ & $53.82 \pm 3.13^{\mathrm{a}}$ & $42.03 \pm 3.00^{b}$ & $39.70 \pm 1.57^{\mathrm{c}}$ \\
\hline & $a^{*}$ & $12.74 \pm 1.73^{\mathrm{a}}$ & $7.10 \pm 1.29^{b}$ & $5.20 \pm 0.98^{c}$ \\
\hline & $b^{*}$ & $29.53 \pm 2.09^{\mathrm{a}}$ & $16.13 \pm 1.02^{b}$ & $11.36 \pm 1.32^{\mathrm{c}}$ \\
\hline \multirow{3}{*}{ Crumb } & $\mathrm{L}^{*}$ & $74.23 \pm 1.73^{\mathrm{a}}$ & $46.70 \pm 1.51^{b}$ & $40.61 \pm 1.10^{\mathrm{c}}$ \\
\hline & $a^{*}$ & $-2.35 \pm 0.28^{c}$ & $2.79 \pm 0.13^{b}$ & $2.90 \pm 0.17^{\mathrm{a}}$ \\
\hline & $\mathrm{b}^{*}$ & $18.64 \pm 0.98^{\mathrm{a}}$ & $13.45 \pm 0.72^{b}$ & $9.08 \pm 0.70^{\mathrm{c}}$ \\
\hline
\end{tabular}

Data are expressed as means $\pm \mathrm{SD}(\mathrm{n}=24)$. Values with the same letter in the same row are not significantly different at $\mathrm{P}<0.05$.

\subsection{Sensory evaluation}

The trained panel detected significant differences in seventeen of the thirty-one attributes evaluated (Table 4).

alt-text: Table 4

Table 4

(i) The presentation of Tables and the formatting of text in the online proof do not match the final output, though the data is the same. To preview the actual presentation, view the Proof.

Mean sensory scores (0-100) of attributes that differed significantly between control and defatted sunflower seed flour fortified muffins.

\begin{tabular}{|c|c|c|c|c|c|}
\hline Parameters & Descriptor & Control & DSSF15 & DSSF30 & Significance of sample (p-value) \\
\hline \multirow{3}{*}{ Appearance } & Surface colour & $44.6 \pm 11.0^{b}$ & $64.6 \pm 21.7^{\mathrm{a}}$ & $70.6 \pm 8.0^{\mathrm{a}}$ & $<0.0001$ \\
\hline & Crumb colour & $16.2 \pm 5.7^{\mathrm{c}}$ & $54.3 \pm 19.8^{b}$ & $61.2 \pm 8.9^{\mathrm{a}}$ & $<0.0001$ \\
\hline & Crumb air bubbles & $8.2 \pm 5.4^{b}$ & $21.3 \pm 10.2^{\mathrm{a}}$ & $19.3 \pm 14.2^{\mathrm{a}}$ & 0.0035 \\
\hline \multirow[t]{2}{*}{ Aroma } & Vanilla & $18.2 \pm 11.2^{\mathrm{a}}$ & $3.6 \pm 7.2^{b}$ & $1.7 \pm 3.8^{b}$ & $<0.0001$ \\
\hline & Egg & $33.1 \pm 9.4^{\mathrm{a}}$ & $9.8 \pm 7.4^{b}$ & $11.1 \pm 8.2^{b}$ & $<0.0001$ \\
\hline
\end{tabular}




\begin{tabular}{|l|l|l|l|l|l|} 
& Veg-Cabbage-Damp & $0.7 \pm 2.0^{\mathrm{b}}$ & $10.8 \pm 10.1^{\mathrm{a}}$ & $15.6 \pm 11.6^{\mathrm{a}}$ & 0.0009 \\
\hline & Milky & $14.1 \pm 8.6^{\mathrm{a}}$ & $0.9 \pm 2.2^{\mathrm{b}}$ & $0.0 \pm 0.1^{\mathrm{b}}$ & $<0.0001$ \\
\hline & Savoury & $0.0 \pm 0.0^{\mathrm{b}}$ & $2.0 \pm 3.8^{\mathrm{b}}$ & $6.9 \pm 5.7^{\mathrm{a}}$ & 0.0030 \\
\hline & Vanilla & $14.2 \pm 8.2^{\mathrm{a}}$ & $4.2 \pm 7.6^{\mathrm{b}}$ & $1.4 \pm 2.7^{\mathrm{b}}$ & 0.0002 \\
\hline & Egg & $26.4 \pm 11.3^{\mathrm{a}}$ & $7.7 \pm 7.1^{\mathrm{b}}$ & $8.1 \pm 2.7^{\mathrm{b}}$ & 0.0004 \\
\hline \multirow{2}{*}{ Taste and flavour } & Bitter & $1.8 \pm 3.3^{\mathrm{c}}$ & $6.8 \pm 6.4^{\mathrm{b}}$ & $11.9 \pm 9.1^{\mathrm{a}}$ & 0.0022 \\
\hline & Ash & $0.0 \pm 0.0^{\mathrm{b}}$ & $0.2 \pm 0.6^{\mathrm{b}}$ & $10.1 \pm 9.4^{\mathrm{a}}$ & 0.0013 \\
\hline & Veg-Cabbage-Damp & $0.0 \pm 0.1^{\mathrm{b}}$ & $8.2 \pm 7.4^{\mathrm{b}}$ & $10.7 \pm 9.7^{\mathrm{a}}$ & 0.0016 \\
\hline & Treacle & $0.0 \pm 0.1^{\mathrm{b}}$ & $4.0 \pm 5.3^{\mathrm{b}}$ & $11.5 \pm 9.1^{\mathrm{a}}$ & 0.0016 \\
\hline \multirow{2}{*}{ Mouthfeel } & Pasting & $37.8 \pm 20.6^{\mathrm{a}}$ & $33.8 \pm 21.7^{\mathrm{ab}}$ & $31.4 \pm 19.8^{\mathrm{b}}$ & 0.0195 \\
\hline & Powdery & $1.5 \pm 4.2^{\mathrm{b}}$ & $6.9 \pm 8.8^{\mathrm{b}}$ & $14.0 \pm 9.7^{\mathrm{a}}$ & 0.0035 \\
\hline After effects & Bitter & $1.7 \pm 2.7^{\mathrm{b}}$ & $7.0 \pm 6.0^{\mathrm{a}}$ & $9.3 \pm 7.1^{\mathrm{a}}$ & 0.0032 \\
\hline
\end{tabular}

Data are expressed as means \pm standard deviation of duplicate scoring sessions with eight panelists. Values with the same letter in the same row are not significantly different at $\mathrm{p}<0.05$.

The following fourteen sensory attributes did not differ significantly between samples: crumb aeration, dry and spongy (appearance); sweet (aroma); sweet, sour, metallic and liquorice (taste and flavour); dry and rate of clearance (mouthfeel); sweet, metallic, numbing and drying (after effects).

In appearance, panellists scored both DSSF fortified muffins as significantly more brown than control for surface colour and crumb colour in accordance with instrumental colour results. DSSF fortified muffins also scored significantly higher than control for crumb air bubbles, which is in accordance with image analysis results. No significant difference was detected among the three recipes for the other appearance attributes crumb aeration $(\mathrm{P}=0.068)$, dry $(\mathrm{P}=0.25)$ and spongy $(\mathrm{P}=0.27)$.

In terms of aroma, DSSF addition at both levels in muffins resulted in significantly lower scores than control for the aroma attributes vanilla, egg and milky. DSSF addition at the highest level resulted in significantly higher scores for savoury aroma than DSSF15 and control muffins (where this savoury aroma was not detected). DSSF addition at both levels led to an aroma described as vegetable-cabbage-damp, which was practically undetected in control muffins. Therefore, DSSF seems to be lowering typical vanilla, egg and milky aromas, while introducing new aromas atypical of muffins, such as savoury and vegetable-cabbage-damp. These are likely to be sulphur containing volatile compounds arising from the high level of sulphur containing amino acids present in the sunflower meal proteins, methionine and cystine (Ivanova, Chalova, Koleva, \& Pishtiyski, 2013).

In taste and retro nasal-flavour, similarly to aroma, the addition of DSSF at both levels resulted in a significant decrease in the vanilla and egg taste and to the detection of a vegetable-cabbage-damp flavour which was absent in control muffins. The addition of DSSF at 30\% resulted in muffins with ash and treacle flavour, while 
these descriptors were not detected in control muffins and scored low in DSSF15 muffins. Increasing DSSF inclusion led to increasing bitter taste, which is common in baked goods containing by-products (Ateş \& Elmac1, 2019; Gómez \& Martinez, 2018) and in baked goods with high protein ingredients (Mohamed, RayasDuarte, Shogren, \& Sessa, 2006; Wendin, Höglund, Andersson, \& Rothenberg, 2017). Statistically, no significant difference was found in sweetness among the recipes $(\mathrm{P}=0.15)$, although a numerical decrease was detected with increasing DSSF content (control $=43.1 \pm 12.3$, DSSF15 $=37.9 \pm 16.3$, DSSF30 $=36.6 \pm 11.3$ ). The scores for the attribute liquorice increased with increasing DSSF inclusion, showing a tendency for significance $(\mathrm{P}=0.0501)$. An effect similar to the one observed in aroma seems to be valid also for taste and flavour. Again, some typical attributes such as vanilla and egg flavour were masked, while other atypical notes were detected (such as vegetable-cabbage-damp, ash, bitter, treacle, liquorice).

In terms of mouthfeel, DSSF30 muffins scored higher than the other two recipes for powdery and lower than control for the attribute pasting. In the after effects, similarly to taste and flavour results, increasing DSSF content led to significantly higher scores for bitterness compared to control. The bitterness detected in taste and after effects for DSSF fortified muffins might be due to the high phenolic content of DSSF (Grasso et al., 2019). No differences in the after effects were found for the other after effect attributes sweet $(\mathrm{P}=0.77)$, metallic $(\mathrm{P}=0.49)$, numbing $(\mathrm{P}=0.14)$ and drying $(\mathrm{P}=0.45)$.

The sensory results indicate that overall a 15\% DSSF inclusion was the most similar to control, as no significant difference was found in six of the seventeen attributes that different significantly (savoury, ash, veg-cabbage, treacle, pasting, powdery). However, since the majority of the sensory attributes (eleven) still differed significantly, the formulations to further develop should contain lower DSSF inclusion levels, such as $5 \%$ or $10 \%$. Sensory quality of DSSF fortified muffins might be improved by modifying this basic recipe to include some flavouring compounds that might help to mask the bitterness as well as the atypical aromas and flavours detected in DSSF fortified muffins.

\section{Conclusion}

This study investigated the effects of DSSF addition at 15\% and 30\% in muffins. DSSF inclusion in muffins resulted in small (although significant) composition changes, such as increased protein and ash content and decreased carbohydrate content. DSSF addition did not affect bake loss, but it increased the muffins' height and pore density, and decreased their springiness. DSSF inclusion had an effect on muffins' colour, making them darker and less yellow than control. In terms of sensory quality, DSSF15 fortified muffins scored closer to control than DSSF30 muffins. DSSF has potential to be exploited as an ingredient in cakes and muffins since its addition mainly led to positive physico-chemical changes. Future reformulation work should focus on the sensory quality of DSSF fortified muffins, testing 5\% and 10\% replacements and carrying out consumers tests. For sweet applications, changes in the formulation should be considered to mask some of the atypical colours, aromas and flavours detected in this study. Due to the savoury and vegetable notes detected in DSSF fortified muffins, it is possible that DSSF might be more suitable for applications in protein-rich savoury products such as hamburgers or vegetarian savoury foods where DSSF addition could be less noticeable.

\section{Declaration of competing interests}


The authors declare that they have no known competing financial interests or personal relationships that could have appeared to influence the work reported in this paper.

\section{Acknowledgements}

The authors are grateful to Les Crompton and Paul Kirton for their help on protein analysis and to the company Planetarians for donating the defatted sunflower seed flour. This research was carried out at the University of Reading and Shuyi Liu's work was supported by the University of Reading UROP scheme.

\section{References}

The corrections made in this section will be reviewed and approved by journal production editor.

Anal, A. K. (2017). Food processing by-products and their utilization. John Wiley \& Sons.

AOAC (2000). Association of official analytical Chemists official methods of analysis (17th ed.). (Washington, DC, USA).

Ateş, G., \& Elmacı, Y. (2019). Physical, chemical and sensory characteristics of fiber-enriched cakes prepared with coffee silverskin as wheat flour substitution. Journal of Food Measurement and Characterization, 13(1), 755-763.

Bajerska, J., Mildner-Szkudlarz, S., Górnaś, P., \& Seglina, D. (2016). The effects of muffins enriched with sour cherry pomace on acceptability, glycemic response, satiety and energy intake: A randomized crossover trial. Journal of the Science of Food and Agriculture, 96(7), 2486-2493.

Bora, P., Ragaee, S., \& Abdel-Aal, E. S. M. (2019). Effect of incorporation of goji berry by-product on biochemical, physical and sensory properties of selected bakery products. LWT-Food Science and Technology, 112.

FAO (2018). FAOSTAT Statistics database - agriculture. http://www.fao.org/faostat/en/\#data/QC.

Gómez, M., \& Martinez, M. M. (2018). Fruit and vegetable by-products as novel ingredients to improve the nutritional quality of baked goods. Critical Reviews in Food Science and Nutrition, 58(13), 21192135 .

González-Pérez, S., Merck, K. B., Vereijken, J. M., van Koningsveld, G. A., Gruppen, H., \& Voragen, A. G. J. (2002). Isolation and characterization of undenatured chlorogenic acid free sunflower (Helianthus annuus) proteins. Journal of Agricultural and Food Chemistry, 50(6), 1713-1719.

Górnaś, P., Juhņeviča-Radenkova, K., Radenkovs, V., Mišina, I., Pugajeva, I., \& Soliven, A., et al. (2016). The impact of different baking conditions on the stability of the extractable polyphenols in 
muffins enriched by strawberry, sour cherry, raspberry or black currant pomace. LebensmittelWissenschaft und -Technologie- Food Science and Technology, 65, 946-953.

Grasso, S., Omoarukhe, E., Wen, X., Papoutsis, K., \& Methven, L. (2019). The use of upcycled defatted sunflower seed flour as a functional ingredient in biscuits. Foods, 8(8), 305.

Heo, Y., Kim, M. J., Lee, J. W., \& Moon, B. (2019). Muffins enriched with dietary fiber from kimchi byproduct: Baking properties, physical-chemical properties, and consumer acceptance. Food Sciences and Nutrition, 7(5), 1778-1785.

Ivanova, P., Chalova, V., Koleva, L., \& Pishtiyski, I. (2013). Amino acid composition and solubility of proteins isolated from sunflower meal produced in Bulgaria. International Food Research Journal, 20(6), 2995.

Marchetti, L., Califano, A., \& Andrés, S. (2018). Partial replacement of wheat flour by pecan nut expeller meal on bakery products. Effect on muffins quality. Lebensmittel-Wissenschaft und Technologie- Food Science and Technology, 95, 85-91.

Martins, Z. E., Pinho, O., \& Ferreira, I. M. P. L. V. O. (2017). Food industry by-products used as functional ingredients of bakery products. Trends in Food Science \& Technology, 67, 106-128.

Matos, M. E., Sanz, T., \& Rosell, C. M. (2014). Establishing the function of proteins on the rheological and quality properties of rice based gluten free muffins. Food Hydrocolloids, 35, 150-158.

Mildner-Szkudlarz, S., Bajerska, J., Górnaś, P., Segliņa, D., Pilarska, A., \& Jesionowski, T. (2016). Physical and bioactive properties of muffins enriched with raspberry and cranberry pomace powder: A promising application of fruit by-products rich in biocompounds. Plant Foods for Human Nutrition, 71(2), 165-173.

Mohamed, A. A., Rayas-Duarte, P., Shogren, R., \& Sessa, D. (2006). Low carbohydrates bread: Formulation, processing and sensory quality. Food Chemistry, 99(4), 686-692.

Mohammed, K., Obadi, M., Omedi, J. O., Letsididi, K. S., Koko, M., Zaaboul, F., ... Liu, Y. (2018). Effect of sunflower meal protein isolate (SMPI) addition on wheat bread quality. Journal of Academia and Industrial Research (JAIR), 6(9), 159.

Pateras, I., Rosenthal, A., Howells, K., \& Marshall, V. (1990). Preliminary investigation into sugar replacement in cake batters. In Carter, R. E. (Ed.), Rheology of food, pharmaceutical and biological materials with general rheology/.

Planetarians. White paper. Planetarians: Helping companies to find better ingredients for people and the planet. Retrieved June 2019, from https://www.planetarians.com/planetarians-technology, 2018.

Ratcliff, R. K. (1977). Nutritional value of sunflower meal for ruminants. Doctoral dissertation at Texas Tech University. 
Salgado, P. R., Molina Ortiz, S. E., Petruccelli, S., \& Mauri, A. N. (2012). Functional food ingredients based on sunflower protein concentrates naturally enriched with antioxidant phenolic compounds. Journal of the American Oil Chemists' Society, 89(5), 825-836.

Sanz, T., Salvador, A., Baixauli, R., \& Fiszman, S. M. (2009). Evaluation of four types of resistant starch in muffins. II. Effects in texture, colour and consumer response. European Food Research and Technology, 229(2), 197-204.

Shchekoldina, T., \& Aider, M. (2014). Production of low chlorogenic and caffeic acid containing sunflower meal protein isolate and its use in functional wheat bread making. Journal of Food Science \& Technology, 51(10), 2331-2343.

Shevkani, K., Kaur, A., Kumar, S., \& Singh, N. (2015). Cowpea protein isolates: Functional properties and application in gluten-free rice muffins. Lebensmittel-Wissenschaft und -Technologie- Food Science and Technology, 63(2), 927-933.

Shevkani, K., \& Singh, N. (2014). Influence of kidney bean, field pea and amaranth protein isolates on the characteristics of starch-based gluten-free muffins. International Journal of Food Science and Technology, 49(10), 2237-2244.

Teh, S.-S., \& Bekhit, A. E.-D. A. (2015). Utilization of oilseed cakes for human nutrition and health benefits. In Hakeem, K. R., Jawaid, M., \& Alothman, O. Y. (Eds.), Agricultural biomass based potential materials (pp. 191-229). Cham: Springer International Publishing.

Wendin, K., Höglund, E., Andersson, M., \& Rothenberg, E. (2017). Protein enriched foods and healthy ageing: Effects of protein fortification on muffin characteristics. Agro Food Industry Hi-Tech, 28(5), $16-18$.

Yegorov, B., Turpurova, T., Sharabaeva, E., \& Bondar, Y. (2019). Prospects of using by-products of sunflower oil production in compound feed industry. Journal of Food Science and Technology-Ukraine, 13(1), 106-113.

\section{Highlights}

- Defatted sunflower seed flour (DSSF) replaced wheat flour in muffins at $15 \%$ and $30 \%$.

- DSSF addition increased muffin protein and ash content and lowered carbohydrates.

- DSSF addition did not affect bake loss but lowered muffin springiness.

- Muffins with DSSF were darker, with more height and more pores than control. 
- The $15 \%$ addition led to a muffin sensory profile closer to control than $30 \%$ inclusion.

\section{Queries and Answers}

Query: Your article is registered as a regular item and is being processed for inclusion in a regular issue of the journal. If this is NOT correct and your article belongs to a Special Issue/Collection please contact j.paulinj@elsevier.com immediately prior to returning your corrections.

Answer: Correct, this article is a regular item

Query: Please confirm that given names and surnames have been identified correctly and are presented in the desired order and please carefully verify the spelling of all authors' names.

Answer: Names and surnames are correct.

Query: Please confirm that the provided email “simona.grasso@ucdconnect.ie” is the correct address for official communication, else provide an alternate e-mail address to replace the existing one, because private e-mail addresses should not be used in articles as the address for communication.

Answer: The provided email address is correct.

Query: Have we correctly interpreted the following funding source(s) and country names you cited in your article: University of Reading, United Kingdom?

Answer: Yes, correct, thank you.

Query: Please check the length of the author initials and confirm if correct. Else provide the updated reference.

Answer: yes, the initials are correct, as per this link:

https://www.sciencedirect.com/science/article/pii/S0924224417302534 